\title{
Use of In vitro Dissolution Testing to Assess Multiple Generic Metformin Tablets
}

\author{
Sze S. Wong ${ }^{1}$ and Suong N. T. Ngo ${ }^{2^{\star}}$ \\ ${ }^{1}$ School of Pharmacy and Medical Sciences, University of South Australia, Adelaide, SA 5000, \\ Australia. \\ ${ }^{2}$ School of Animal \& Veterinary Sciences, The University of Adelaide, Roseworthy, SA 5371,
} Australia.

Authors' contributions

This work was carried out in collaboration between both authors. Author SSW performed the collection and analysis of the data. Author SNTN managed the analyses of the data, assisted with data collection, managed the literature searches and wrote the first draft of the manuscript. Both authors read and approved the final manuscript.

Article Information

DOI: $10.9734 / J P R I / 2018 / 39508$

Editor(s):

(1) Neena Philips, Professor, Biology, Fairleigh Dickinson University, New Jersey, USA.

Reviewers:

(1) Endang Diyah Ikasari, Yayasan Pharmasi College of Pharmacy, Indonesia. (2) Anna Gumieniczek, Medical University of Lublin, Poland. (3) Larissa Sakis Bernardi, Universidade Estadual do Centro-Oeste, Brazil. (4) Nidhi Mishra, Indian Institute of Information Technology, India. Complete Peer review History: http://www.sciencedomain.org/review-history/23621

Short Research Article

Received $3^{\text {rd }}$ January 2018

Accepted $8^{\text {th }}$ March 2018

Published 13 ${ }^{\text {th }}$ March 2018

\section{ABSTRACT}

Aims: Metformin is a high-solubility and low-permeability drug that is widely used as an oral antidiabetic medication. In many countries, metformin is available as multiple generic formulations, with over 10 registered products, which are approved to be dispensed interchangeable. The aims of this study were to assess the in vitro dissolution profiles of a range of commercial brands of metformin hydrochloride tablets under a range of in vitro conditions and to determine whether differences in in vitro dissolution can be detected under a range of conditions.

Methodology: Single and multiple (2 or 4) tablets from all brands were tested in both $\mathrm{pH} 6.8$ and $0.1 \mathrm{M} \mathrm{HCl}$ (gastric $\mathrm{pH}$ ) dissolution medium and collected samples were analysed by highperformance liquid chromatography.

Results: At least three distinct dissolution profiles were seen, designated slow, medium and fast 
released profiles. The innovator product, Glucophage ${ }^{(B)}$ exhibited a medium released profile while Glucohexal $^{\circledR}(\mathrm{G} 1)$ and Diaformin $^{\circledR}$ (G3) displayed a fast released and a slow released profile respectively. The differences in the dissolution profiles were more apparent in the $0.1 \mathrm{M} \mathrm{HCl}$ medium and a higher degree of disparity between the dissolution profiles was observed when the number of tablets in each dissolution flask increased.

Conclusion: The results indicated that multiple registered versions of metformin have different dissolution profiles that can be detected even under standard in vitro conditions. However, all formulations were extensively dissolved within 45 minutes, suggesting that the in vivo performance of the different brands are not likely to differ to a clinically significant extent.

Keywords: Metformin; bioequivalence; dissolution testing; HPLC.

\section{INTRODUCTION}

In recent years, the number of generic versions of important prescription medicines has increased significantly. The registration of generic brands is generally supported by comparison against the market leader, but rarely are the generic brands tested against each other. The first formulation of a new drug to come on the market is known as an innovator, which is generally the same or very similar to the formulation with which the pivotal phase III studies were performed. Generic products contain the same active ingredient as the innovator in the same pharmaceutical form although the excipients may vary. A generic product may be considered to be bioequivalent to the innovator when they show an equal rate or extent of absorption into the systemic circulation [1]. Statistically the $90 \%$ confidence interval for the maximum plasma concentration (Cmax) and the area under the concentration-time curve (AUC) of the generic must be entirely within the $80 \%-125 \%$ range for the Cmax and AUC of the innovator. Practically, the generics must generally have mean Cmax and AUC values within $10 \%$ of the innovator product to achieve the regulation standard [2]. In oral preparations, the rate and extent of drug dissolution under standard condition can be used as a guide to the bioequivalence of the different formulations, for example greater than $70 \%$ dissolved in 45 minutes $[3,4]$.

Metformin is a biguanide with antihyperglycemic actions, which is widely used in the treatment of type II diabetes. In Australia, there are currently 13 registered formulations of metformin $500 \mathrm{mg}$ tablets, which can be dispensed interchangeable. Metformin is a Biopharmaceutics Classification System BSC Class 3 drug (high solubility/poor permeability), and is recommended as first-line therapy for all newly diagnosed diabetic patients regardless of age [5]. It is available as its hydrochloride salt in both immediate and modified release dosage forms. Its physical properties include a hydrophilic base with pKa of 12.4 , a low molecular weight (MW of $129.17 \mathrm{Da}$ ), aqueous solubility $>100 \mathrm{mg} / \mathrm{ml}$ at physiological $\mathrm{pH}$ range $(\mathrm{pH} 1.2-9.5)$, and a $\log D$ of -3.37 at $\mathrm{pH} 4$. Thus, it is expected to have limited, passive diffusion through cell membranes. Based on Caco-2 studies, the proposed mechanism of absorption of metformin was $91-95 \%$ passive paracellular and 5-9\% transcellular $[6,7]$.

While the registration of any new generic oral medicine is generally based on bioequivalence testing against a single innovator product, the relative performance of the various generic formulations is not routinely tested. The importance of assessing bioequivalence between different formulations of the same drug has been long recognised as a major medical issue. For example, it has been reported that some patients experienced a relapse in psychotic symptoms after switching from brand-name clozapine to a generic formulation [8]. Given that generic products are approved via comparison against the innovator only, one could argue that switching from one generic version to another might give rise to even more complications. More complications would be due to the potentially greater disparity between two generic products than between any single generic product and the innovator. Drugs that have been reported to show a variation in effects and toxicity in patients in relation to the use of generics are those with a narrow therapeutic index including carbamazepine, phenytoin and antiarrhythmic medications $[9,10]$.

A biowaiver approach allows the approval of changes to a drug product that are predicted not to affect bioequivalence, minimising review burden on regulators and avoiding unnecessary clinical studies, expense, and delay for the 
sponsor. According to the BSC, biowaiver is recognised as applicable for BSC class I drugs (high solubility/high permeability) based on comparative in vitro drug release [1]. In the case of metformin and BSC class 3 drugs, in vitro-in vivo correlation depends on all key PK parameters that define their absorption profile, including drug release, permeability and gastrointestinal transit time. Thus, drug release times must be within the boundaries of the intestinal absorption window for two formulations to be bioequivalent. Part of the reason is that the controlling factors in the absorption process from the drug product are not just the drug substance solubility.

In vitro-in vivo correlations can be used to predict the rate of absorption of a drug in vivo by performing a simple in vitro dissolution test. Whether a correlation exists between the two depends on the solubility and permeability of the drug tested. For drugs with high solubility and permeability such as metformin, dissolution testing can be used to determine that the dosage form is effectively delivering the drug into solution and the correlation between this and in vivo performance will depend on the ratelimiting step of the dissolution and absorption process.

In the present study, commercially available different brands of metformin 500mg tablets were subjected to dissolution testing to assess their relative in vitro performance. The aims of this study were to assess the in vitro dissolution profiles for multiple generic metformin tablets and to determine whether differences in in vitro dissolution can be detected under in vitro pharmacopeial conditions and under conditions of high tablet load.

\section{MATERIALS AND METHODS}

\subsection{Materials}

Various brands of metformin 500mg tablets (Glucophage $\AA$, Glucohexal $\AA$, Diaformin $\AA$, Biochemie $\AA$, Healthsense $\AA$, Terry White $\AA$, GenRx $($ ) were purchased from a local wholesaler and Metformin $\mathrm{HCl}$ powder were purchased from Sigma Chemical Company, Castle Hill, Australia. Otho-phosphoric acid was obtained from Laboratory Supplies, Poole, England and acetonitrile was obtained form Waters Associates, Lane Cove, NSW, Australia. Milli-Q water was made in house using the Milli$\mathrm{Q}$ water purifier system (Millipore/Waters USA).
All other chemicals were purchased commercially and were of analytical grade.

\subsection{Dissolution Testing}

The dissolution testing was conducted using the basket apparatus as per the British Pharmacopeia (BP 2002) guidelines for the dissolution of metformin tablets: at rotation speed $100 \mathrm{rpm}$, dissolution volume $900 \mathrm{ml}$ at $36.5^{\circ} \mathrm{C}$. For each formulation, the dissolution test was performed with 1, 2 and 4 tablets. Tests were conducted at least five times for 1 tablet per flask and twice for all others. For each brand, at each tablet load, dissolution profiles were determined at $\mathrm{pH} 6.8$ (physiological $\mathrm{pH}$ of intestine) and $\mathrm{HCl}$ $0.1 \mathrm{M}$ (gastric acidic $\mathrm{pH}$ ). Samples $(5 \mathrm{ml})$ of dissolution media were collected at $0,5,10,15$, $20,25,30,45$ and $60 \mathrm{~min}$ and analysed by HPLC.

In addition, tests for physical characteristics of the tablets (including hardness, weight variation, friability) were also performed in accordance with the British Pharmacopeia BP specifications.

\subsection{HPLC analysis}

A validated HPLC method involving UV detection was used to measure the concentration of metformin in the dissolution medium, utilising the HPLC SIL10A Shimadzu system, with LC10 AT Pump and Auto sampler, and Model SPD 6A UV Spectrophotometric detector, on a Alltech C18 5 UHP, stainless steel $250 \mathrm{~mm} \times 4.6 \mathrm{~mm}$ column ( supplied by Box Hill, Australia). The HPLC conditions include detector wavelength of $225 \mathrm{~nm}$ using a mobile phase containing acetonitrile, milliQ water and $0.1 \mathrm{M}$ orthophosphoric acid : acetonitrile at a ratio of $50: 50: 1$ adjusted to $\mathrm{pH}$ 5.75 with triethylamine and $5 \mu \mathrm{l}$ injection volume. The retention time of metformin under these conditions was found to be approximately 6-8 min. A calibration curve for metformin was constructed over the range of 0.1 to $0.6 \mathrm{mg} / \mathrm{ml}$.

For each formulation, the dissolution test was performed with 1, 2 and 4 tablets at both $\mathrm{pH} 6.8$ and $\mathrm{HCl} 0.1 \mathrm{M}$ (gastric $\mathrm{pH}$, approximately $\mathrm{pH} 1$ ), the later two mimic stressed conditions (nonideal conditions). The dissolution test was conducted at least five times for 1 tablet per flask and twice for each of the other dissolution profiles. For drug release (\%) versus time, testing 1,2 , and 4 tablets at different conditions, Microsoft Excel software was used to calculate the values of the means and standard deviations. 


\subsection{Statistical Analysis}

Statistical analysis was performed using Microsoft Excel software. Drug releases (\%) were compared between innovator Glucophage ${ }^{\circledR}$ and formulations $\mathrm{G} 1, \mathrm{G} 2, \mathrm{G} 3$, and G4 over the $60 \mathrm{~min}$ dissolution. Drug releases (\%) for testing 1 tablet per flask, in $\mathrm{pH} 6.8$ and gastric acidic $\mathrm{pH}$, expressed as mean $\pm S D$ of at least five measurements were analysed by Student's $t$ test. A $P$ value $<.05$ was considered to be significant. Drug releases (\%) for testing 2, and 4 tablets per flask were expressed as mean \pm SD of at least 2 measurements.

\section{RESULTS AND DISCUSSION}

Dissolution profiles for each formulation of metformin tablets, including Biochemie ${ }^{\circledR}(\mathrm{G} 4)$, Diaformin $\AA$ (G3), Glucohexal ${ }^{\circledR}(\mathrm{G} 1)$, Innovator Glucophage and Healthsense $\AA$, Terry White $\AA$ and $\operatorname{GenRx}{ }^{\circledR}$ (G2) in different conditions are given in Figs. 1-6. Healthsense $\AA$, Terry White $\AA$ and $\mathrm{GenRx}{ }^{\circledR}$ are all considered to be formulation G2 since they are from the same formulation. The results for testing 1 tablet are expressed as mean \pm standard deviation (SD) of at least five measurements.

Figs. 1 and 2 showed that under standard conditions, testing 1 tablet at $\mathrm{pH} \quad 6.8$ (physiological $\mathrm{pH}$ of intestine) or $\mathrm{HCl} 0.1 \mathrm{M}$ (gastric acidic $\mathrm{pH}$ ), at least three distinct dissolution profiles were obtained for the five formulations tested. While formulation G1 exhibited a very fast profile with nearly $100 \%$ of the tablet content dissolved within the first 10 min, formulations G4, G3 and G2 showed a slow profile with less than $60 \%$ of the tablet content dissolved within this time. The dissolution profile for the innovator Glucophage ${ }^{\circledR}$ was located between the fast and the slow formulations. Overall, for the innovator Glucophage ${ }^{\circledR}$ and formulation $\mathrm{G} 1,100 \%$ drug release is obtained within $15 \mathrm{~min}$ and $10 \mathrm{~min}$ respectively, whereas it is over 30 min for $100 \%$ of the drug released from formulations G2, G3, and G4.

In this study, the drug release of metformin tablets were tested in two different in vitro $\mathrm{pH}$ environments in order to correlate in vitro drug release with in vivo metformin absorption from the small intestine and the upper $\mathrm{Gl}$ tract, as $\mathrm{pH}$ 6.8 medium mimics the intestinal biological environment. The small intestine is the major site of drug absorption for orally administered drugs, and $\mathrm{HCl} 0.1 \mathrm{M}$ medium would mimic the acidic biological environment of the stomach, another $\mathrm{GI}$ site from which drug is absorbed. How quickly a drug dissolved into solution at these sites prior to being absorbed will affect overall drug absorption, plasma concentration, and oral bioavailability.

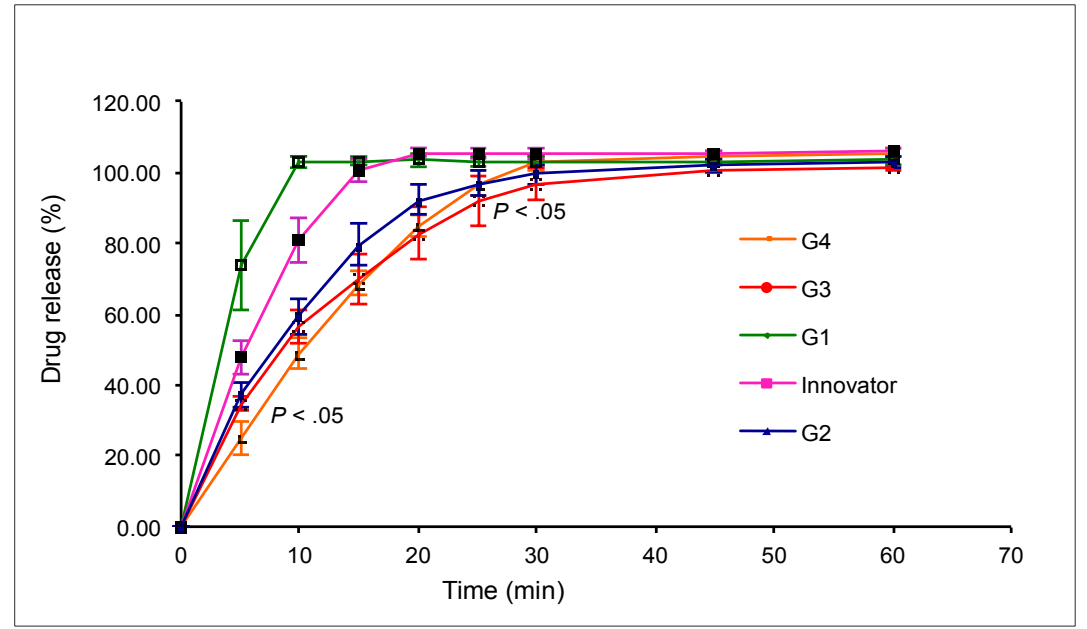

Fig. 1. Dissolution profiles for one tablet per flask at pH 6.8 (physiological $\mathrm{pH}$ of intestine) for individual metformin tablet formulations, expressed as mean \pm SD of at least five measurements. Mean drug release (\%) of G4 and G3 significantly lower than Innovator Glucophage ${ }^{\circ}$ at $P<.05$ by Student's $\boldsymbol{t}$ test

G4: Biochemie $\AA$; G3: Diaformin $\AA$; G1: Glucohexal $\AA$; Innovator: Glucophage $\AA$; G2: Healthsense $\AA$, Terry White $\Theta$ and $\operatorname{GenRx} \Theta$, these three formulations are all considered to be $\mathrm{G} 2$ since they are from the same formulation 
As shown in Fig. 2, in $\mathrm{HCl} 0.1 \mathrm{M}$ medium (gastric acidic $\mathrm{pH}$ ), for most formulations tested, the dissolution was slower as compared to that at $\mathrm{pH}$ 6.8 (physiological pH of intestine). Metformin is a basic compound with pKa of 12.4; practically drug release is increased at acidic $\mathrm{pH}$ due to increased solubility. Metformin has a low molecular weight (MW of $129.17 \mathrm{Da}$ ), aqueous solubility $>100 \mathrm{mg} / \mathrm{ml}$ at physiological $\mathrm{pH}$ range $(\mathrm{pH} 1.2-9.5)$, and $\mathrm{a} \log D$ of -3.37 at $\mathrm{pH} 4$. Thus, it is expected to have limited, passive diffusion through cell membranes. Based on Caco-2 studies, the proposed mechanism of absorption of metformin was $91-95 \%$ passive paracellular and $5-9 \%$ transcellular $[6,7]$. The unexpected results of slower metformin release observed at gastric acidic medium might be possibly due to some inherent property of the excipients in different formulations that interfere with metformin peak height or area owing to their inherent properties at acidic $\mathrm{pH}$. In addition, metformin's peak height and peak area can also be interfered by medium's $\mathrm{pH}$. This in turn can cause disparity in in vitro drug release profile of the test formulations in $\mathrm{pH} 6.8$ medium compared to $\mathrm{HCl} 0.1 \mathrm{M}$ (gastric acidic $\mathrm{pH}$ ) medium. However, no significant variations were detected in metformin retention time or peak height/area from the calibration curves constructed using $\mathrm{pH}$ 6.8 versus $\mathrm{HCl} 0.1 \mathrm{M}$ medium in the current study. Thus variability in absorption spectrum is unlikely to cause these unexpected results. It has been reported that drug release studies on metformin tablets sourced from different territories often showed inconsistent drug release characteristics [11]. Thus, different manufacturing processes may possibly be another factor, which contributes to inconsistent drug release.

At $\mathrm{HCl} 0.1 \mathrm{M}$ medium (gastric acidic $\mathrm{pH}$ ), it was noted that while the release rates for G4 and G3 are very dissimilar and differ to innovator Glucophage ${ }^{\circledR}$, release rate for $\mathrm{G} 1$ also differs greatly to the innovator Glucophage ${ }^{\circledR}$ (Fig. 2). No significant differences in hardness, weight variation, and friability were detected. All formulations met the BP specifications for these tests.

It was important to note that testing more than one tablet in the same flask may affect the overall surface area and the positions of the tablets, which may in turn affect the accuracy of the dissolution results. This is unlikely to be the case here for metformin given its high solubility in $\mathrm{pH} 6.8$ medium, as demonstrated previously in the results of the dissolution test performed at $\mathrm{pH}$ 6.8 (Fig. 1) and also in Fig. 3. In addition, metformin has been reported to be highly soluble with $>100 \mathrm{mg} / \mathrm{ml}$ in the $\mathrm{pH}$ range of $1.2-9.5$ as described earlier $[6,7]$. In the present study, two $500 \mathrm{mg}$ tablets $(1000 \mathrm{mg})$ of reasonably small size were tested at rotation speed of 100rpm, in dissolution volume $900 \mathrm{ml}$ at $\mathrm{pH} 6.8$ and gastric acidic $\mathrm{pH}$, with considerable care regarding the position of the tablet in the baskets. In comparison to testing 1 tablet, this condition should not alter the tablet surface or position character. We aim to test the in vitro dissolution behaviour under conditions of 2 and 4 tablet load because this is similar to a situation when metformin tablets are taken with a relatively small volume of water. As shown in Figs. 3, 4, 5 and 6, the dissolution of most products tested was slower with the curves shifted to the right in comparison to testing 1 tablet. A higher intertablet variation was also observed.

A recently proposed in Silico approach for bioequivalence study has reported that for BSC class 3 drugs, there is no impact of in vitro drug release rate on in vivo performance over a broad defined range of metformin release rates [11]. In this study, metformin (500 mg) generic and reference formulations were investigated, the model predicted bioequivalence based on in vitro drug release, permeability and GI transit time, and results compared with data from bioavailability clinical studies. This approach suggested that metformin formulations that release $100 \%$ in $\leq 2$ hours in vitro are indicated to be bioequivalent. Moreover, metformin tablet generic formulations, which exhibited dissimilar drug release profiles to the reference formulation during formulation development have been demonstrated as bioequivalent and displayed comparable plasma AUC and Cmax in subsequent bioavailability clinical studies $[12,13]$. Metformin is also a well established and widely studied drug with a wide therapeutic index, marked changes in therapeutic efficacy due to changes in systemic absorption are unlikely to occur if drug release times are within the $\mathrm{Gl}$ absorption boundaries.

Overall, the results suggested that under stressed condition such as high tablets/fluid ratios, the disparity in the in vivo dissolution might be more significant. However, as all formulations were extensively dissolved within 45 minutes, in both standard in vitro conditions, 1 table per flask in pH 6.8 medium (physiological $\mathrm{pH}$ of intestine) or 


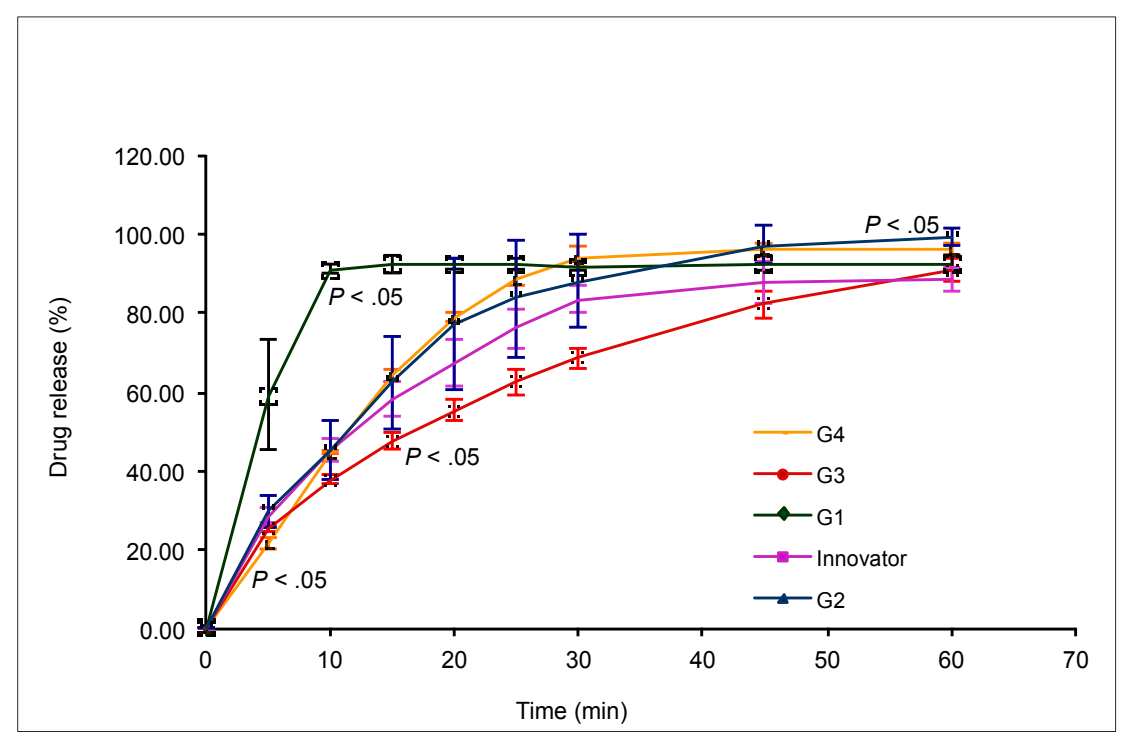

Fig. 2. Dissolution profiles for one tablet per flask at gastric acidic $\mathrm{pH}(\mathrm{HCl} 0.1 \mathrm{M})$ for individual metformin tablet formulations, expressed as mean \pm SD of at least five measurements. Mean drug release (\%) of G4, G3, G2 and G1 significantly different to Innovator Glucophage $\circledast$ at $P<$ .05 by Student's $t$ test

G4: Biochemie $\AA$; G3: Diaformin $\AA$; G1: Glucohexal $\AA$; Innovator: Glucophage $\AA$; G2: Healthsense $\AA$, Terry White $\Theta$ and $\operatorname{GenRx} \AA$, these three formulations are all considered to be $\mathrm{G} 2$ since they are from the same formulation.

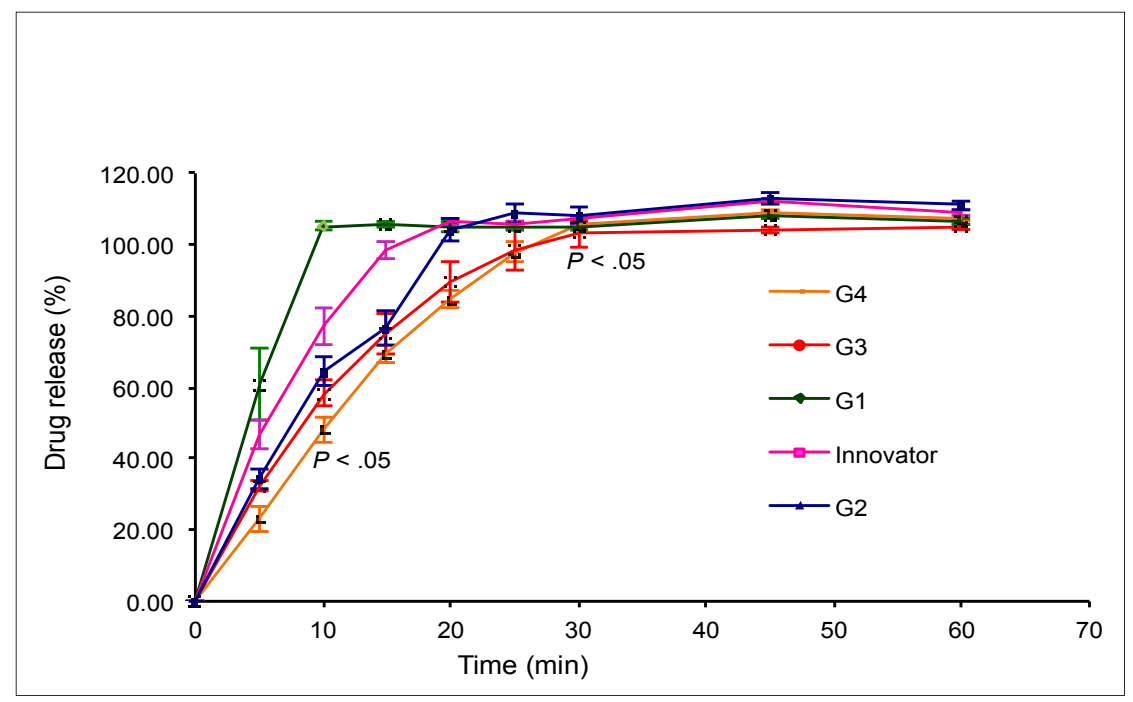

Fig. 3. Dissolution profiles for two tablets per flask at pH 6.8 (physiological pH of intestine) for individual metformin tablet formulations, expressed as mean \pm SD of at least two measurements. Mean drug release (\%) of G4 and G3 significantly lower than Innovator Glucophage $₫$ at $P<.05$ by Student's $\boldsymbol{t}$ test

G4: Biochemie $\AA$; G3: Diaformin $\Theta ;$; 1: Glucohexal $\AA$; Innovator: Glucophage $\AA$; G2: Healthsense $\AA$, Terry White $\Theta$ and $\operatorname{GenRx} \otimes$, these three formulations are all considered to be $\mathrm{G} 2$ since they are from the same formulation.

$\mathrm{HCl} 0.1 \mathrm{M}$ medium (gastric acidic $\mathrm{pH}$ ), and in stress conditions of high tablet load, the findings suggested that there are unlikely to be clinically significant differences in terms of in vivo performance. 


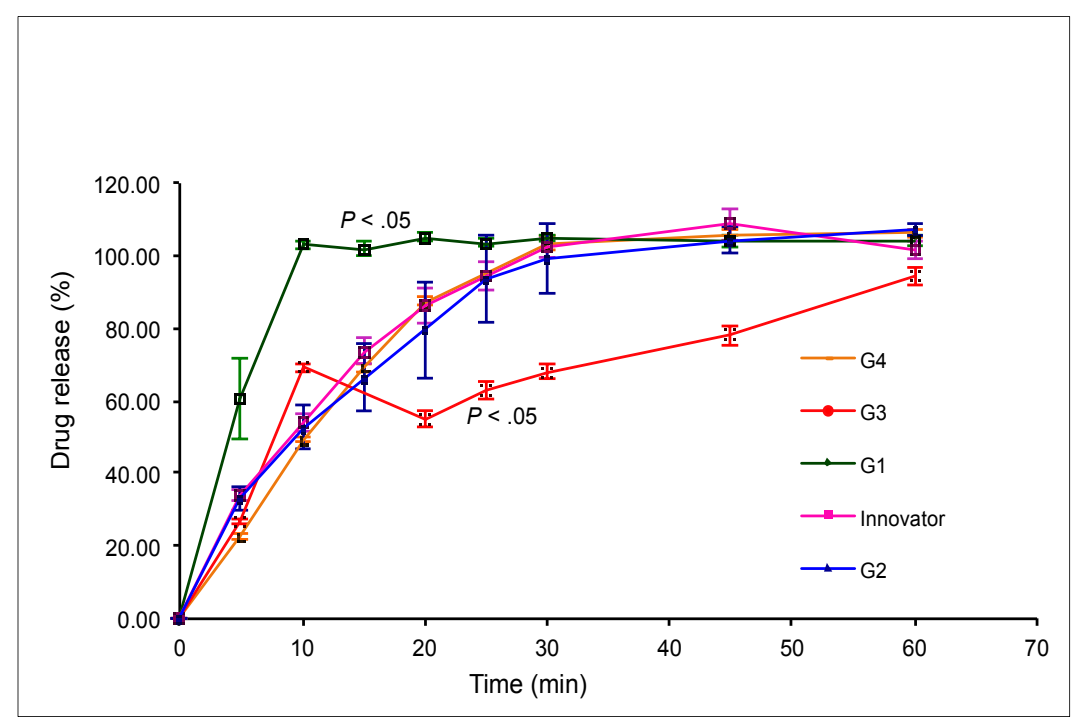

Fig. 4. Dissolution profiles for two tablets per flask at gastric acidic $\mathrm{pH}(\mathrm{HCl} 0.1 \mathrm{M})$ for individual metformin tablet formulations, expressed as mean \pm SD of at least two measurements. Mean drug release (\%) of G3 and $\mathbf{G 1}$ significantly different to Innovator Glucophage $\circledast$ at $P<.05$ by Student's $\boldsymbol{t}$ test

G4: Biochemie $\AA$; G3: Diaformin $\AA$; G1: Glucohexal $\Theta$; Innovator: Glucophage $\AA$; G2: Healthsense $\AA$, Terry White $\Theta$ and $\operatorname{GenRx} \Theta$, these three formulations are all considered to be $\mathrm{G} 2$ since they are from the same formulation.

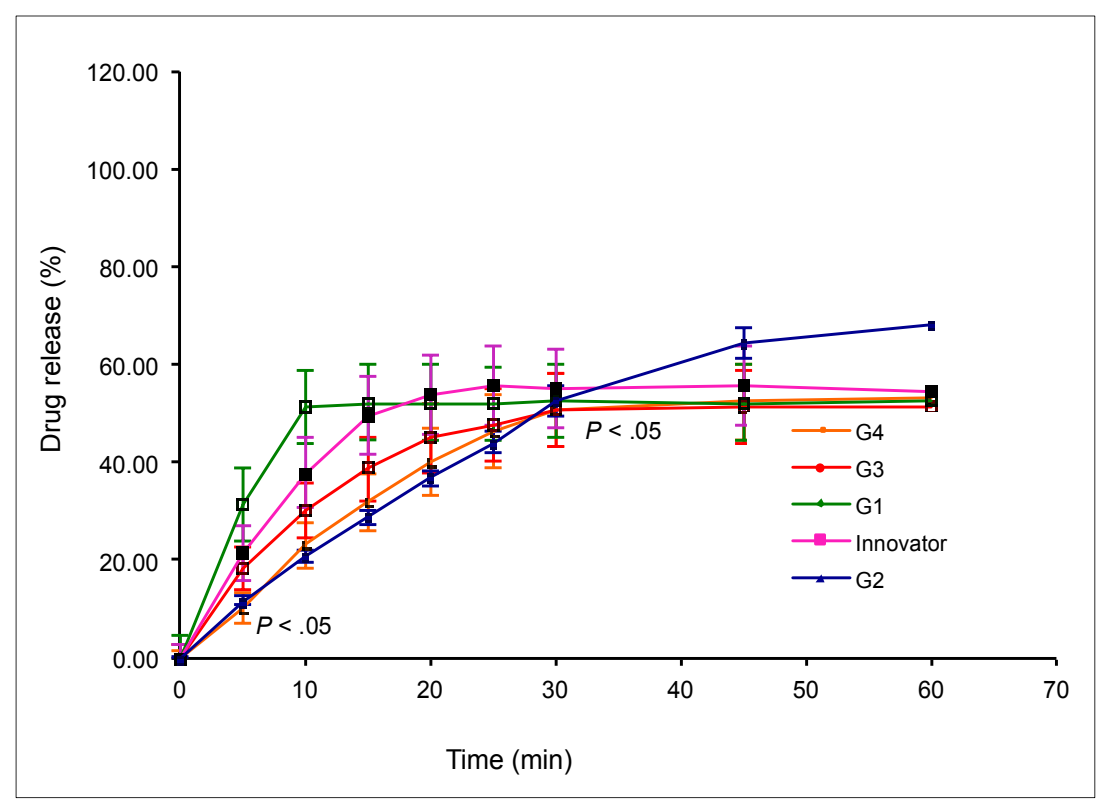

Fig. 5. Dissolution profiles for four tablets per flask at pH 6.8 (physiological pH of intestine) for individual metformin tablet formulations, expressed as mean \pm SD of at least two measurements. Mean drug release (\%) of G4 and G3 significantly lower than Innovator Glucophage ${ }^{\circ}$ at $P<.05$ by Student's $t$ test. $G 2$ drug release also markedly different to Innovator Glucophage ${ }^{\circledR}$

G4: Biochemie $\AA$; G3: Diaformin $\AA$; G1: Glucohexal $\AA$; Innovator: Glucophage $\AA$; G2: Healthsense $\AA$, Terry White $\Theta$ and $\operatorname{GenRx}{ }^{\circledR}$, these three formulations are all considered to be $\mathrm{G} 2$ since they are from the same formulation. 


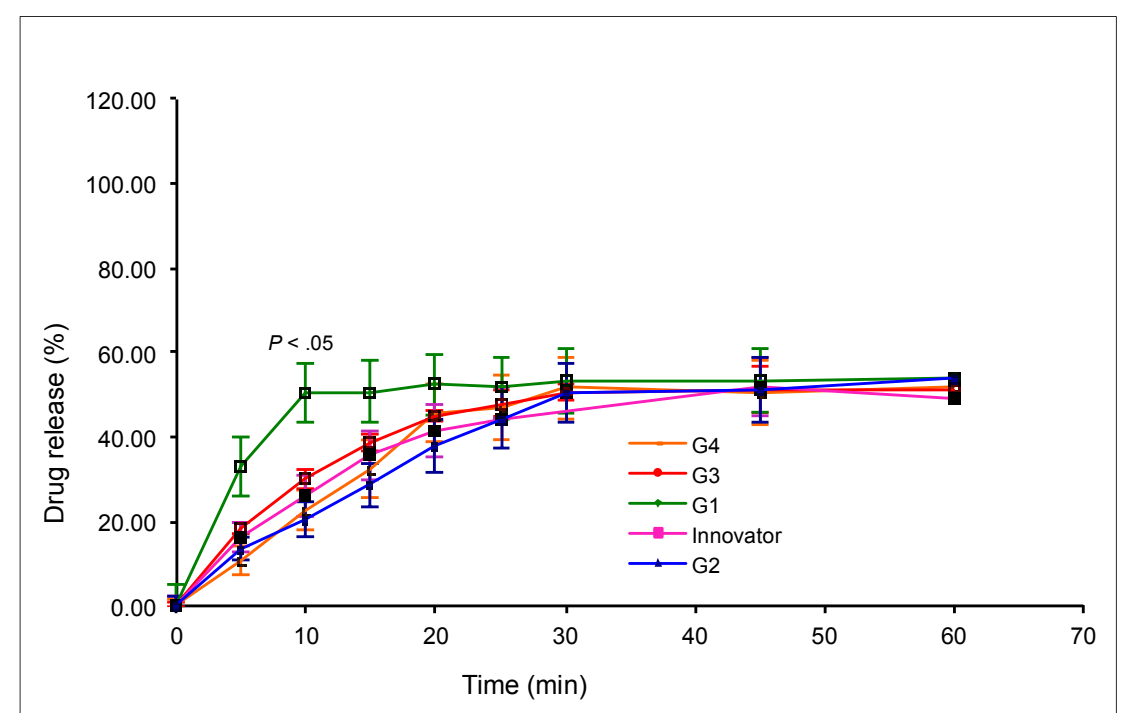

Fig. 6. Dissolution profiles for four tablets per flask at gastric acidic $\mathrm{pH}(\mathrm{HCl} 0.1 \mathrm{M})$ for individual metformin tablet formulations, expressed as mean \pm SD of at least two measurements. Mean drug release (\%) of G1 significantly different to Innovator Glucophage ${ }^{\circ}$ at $P<.05$ by Student's $t$ test

G4: Biochemie $\odot$; G3: Diaformin $\Theta ;$; 1: Glucohexal $\odot$; Innovator: Glucophage $\AA$; G2: Healthsense $\AA$, Terry White $\Theta$ and $\operatorname{GenRx} \AA$, these three formulations are all considered to be $\mathrm{G} 2$ since they are from the same formulation

Collectively, there is significant variation between the dissolution profiles of multiple registered versions of metformin that can be detected even under standard in vitro conditions. Different metformin formulations also exhibited a higher degree of disparity in $0.1 \mathrm{M} \mathrm{HCl}$ medium and under high tablet load condition testing multiple (2 or 4) tablets per flask, with drug release profiles of the formulation $\mathrm{G} 1$, in particular being markedly different from that of the innovator Glucophage ${ }^{\circledR}$.

\section{CONCLUSION}

In conclusion, multiple registered versions of metformin displayed different dissolution profiles that can be detected even under standard in vitro conditions, at $\mathrm{pH} 6.8$ (physiological $\mathrm{pH}$ of intestine) and gastric acidic $\mathrm{pH}(\mathrm{HCl} 0.1 \mathrm{M})$. However, all formulations were extensively dissolved within 45 minutes, suggesting that the in vivo performance of the different brands are not likely to differ to a clinically significant extent. Although considerable variability is detected in the 60 min drug release of theses formulations, bioequivalence between metformin generic formulations with commonly used excipients is high.

\section{CONSENT}

It is not applicable.

\section{ETHICAL APPROVAL}

It is not applicable.

\section{ACKNOWLEDGEMENT}

The authors would like to thank Prof Allan Evans, Provost, University of South Australia for his initial input on this work and his kind support for the publication of the data from this research project.

\section{COMPETING INTERESTS}

Authors have declared that no competing interests exist.

\section{REFERENCES}

1. Guidance for Industry. Bioavailability and Bioequivalence Studies for Orally Administered Drug Products General Consideration. US 
Department of Health and Human Services Food and Drug Admi nistration FDA; 2003.

Available:http://www.fda.gov/downloads/Dr ugs/Guidances/ucm070124.pdf

2. Evans AM. Essential CPE: Bioequivalence Pharmaceutical Society of Australia; 2000.

3. Amidon $G L$, Lennernas $H$, Shah VP, Crison JR. A theoretical basis for a biopharmaceutical drug classification: The correlation of in vitro drug product dissolution and in vivo bioavailability. Pharmaceutical Research. 1995;12(3): 413-420.

4. Bertil A. Oral drug absorption: Prediction and assessment. New York: Marcel Dekker, Inc.; 2000.

5. Nathan DM, et al. Management of hyperglycaemia in type 2 diabetes: A consensus algorithm for the initiation and adjustment of therapy. Diabetes Care. 2006;29:1963-1972.

6. Bretnall AE, Clarke GS. Metformin hydrochloride. In: Britain HG, editor. Analytical profiles of drug substances and excipients. California: Academic Press. 1998;243-293.

7. Proctor WR, Bourdet DL, Thakker DR. Mechanism underlying saturable intestinal absorption of metformin. Drug Metab. Dispos. 2008;26:1650-1658.

8. Mofsen R, Balter J. Case reports of the reemergence of psychotic symptoms after conversion from brand-name clozapine to a generic formulation. Clinical Therapeutics. 2001;23(10):1720-1731.

9. Reiffel JA. Issues in the use of generic antiarrhythmic drugs [Review]. Current Opinion in Cardiology. 2001;16(1):23-29.

10. Besag FMC. Is genetic prescribing acceptable in epilepsy? Drug Safety. 2000;23(3):173-182.

11. Crison JR, Timmins $P$, Keung A, Upreti VV, Boulton DW, Scheer BJ. Biowaiver approach for Biopharmaceutics classification system class 3 compound metformin hydrochloride using in silico modelling. J. Pharm. Sci. 2012;101:17731782.

12. Cheng CL, Yu LX, Lee HL, Yang CY, Lue $\mathrm{CS}$, Chou $\mathrm{CH}$. Biowaiver extension potential to BCS class III high solubility-low permeability drugs: bridging evidence for metformin immediate-release tablet. Eur. J. Pharm. Sci. 2004;22:297-304.

13. Ring A, Morris TB, Hohl K, Schall R. Indirect bioequivalence assessment using network meta-analyses. Eur. J. Clin. Pharmacol. 2014;70:947-955.

(C) 2018 Wong and Ngo; This is an Open Access article distributed under the terms of the Creative Commons Attribution License (http://creativecommons.org/licenses/by/4.0), which permits unrestricted use, distribution, and reproduction in any medium, provided the original work is properly cited.

Peer-review history:

The peer review history for this paper can be accessed here: http://www.sciencedomain.org/review-history/23621 